\title{
Cost-effectiveness analysis of Chlamydia trachomatis screening in Dutch pregnant women
}

\author{
G. I. J. G. Rours ${ }^{1,2}$, Tamar Anne Smith-Norowitz ${ }^{3}$, Jared Ditkowsky'3, Margaret R. \\ Hammerschlag ${ }^{3}$, R. P. Verkooyen ${ }^{2}$, R. de Groot ${ }^{1}$, H. A. Verbrugh ${ }^{2}$, M. J. Postma ${ }^{4}$
}

${ }^{1}$ Department of Paediatric Infectious Diseases and Immunology, Erasmus MC, Rotterdam, The Netherlands, 2Department of Medical Microbiology and Infectious Diseases, Erasmus MC, Rotterdam, The Netherlands, ${ }^{3}$ Department of Pediatrics, State University of New York Downstate Medical Center, Brooklyn, NY 11203, USA, 4 Unit of PharmacoEpidemiology \& PharmacoEconomics ( $\left.\mathrm{PE}^{2}\right)$, Department of Pharmacy, University of Groningen, Groningen, The Netherlands

Chlamydia trachomatis infections during pregnancy may have serious consequences for women and their offspring. Chlamydial infections are largely asymptomatic. Hence, prevention is based on screening. The objective of this study was to estimate the cost-effectiveness of $C$. trachomatis screening during pregnancy. We used a health-economic decision analysis model, which included potential health outcomes of $C$. trachomatis infection for women, partners and infants, and premature delivery. We estimated the cost-effectiveness from a societal perspective using recent prevalence data from a population-based prospective cohort study among pregnant women in the Netherlands. We calculated the averted costs by linking health outcomes with health care costs and productivity losses. Cost-effectiveness was expressed as net costs per major outcome prevented and was estimated in base-case analysis, sensitivity, and scenario analysis. In the base-case analysis, the costs to detect 1000 pregnant women with $C$. trachomatis were estimated at $€ 527,900$. Prevention of adverse health outcomes averted $€ 626,800$ in medical costs, resulting in net cost savings. Sensitivity analysis showed that net cost savings remained with test costs up to $€ 22$ (test price $€ 19$ ) for a broad range of variation in underlying assumptions. Scenario analysis showed even more cost savings with targeted screening for women less than 30 years of age or with first pregnancies only. Antenatal screening for $C$. trachomatis is a cost-saving intervention when testing all pregnant women in the Netherlands. Savings increase even further when testing women younger than 30 years of age or with pregnancies only.

Keywords: Chlamydia trachomatis, cost-effectiveness, pregnancy, preterm delivery, screening

Key messages box: 1 . Screening pregnant women for $C$. trachomatis is cost saving for the Netherlands, 2 . Chlamydia screening is even more cost saving when aiming at women $<30$ years or with first pregnancies, 3 . This is the first CEA of antenatal $C$. trachomatis screening that includes preterm delivery

\section{Introduction}

Chlamydia trachomatis is the most common bacterial sexually transmitted pathogen in industrialized countries. About $80 \%$ of infected women remain asymptomatic. Asymptomatic chlamydial infection poses risks of pregnant women due to pelvic inflammatory disease (PID), infertility, and ectopic pregnancy and may lead to neonatal conjunctivitis and respiratory tract infection. Moreover, chlamydial infection may have an adverse effect on pregnancy outcome regarding preterm delivery. ${ }^{1-5}$ These complications lead to major health costs, which can only be prevented by active case finding and early treatment of infection.

Correspondence to: Tamar Anne Smith-Norowitz, Department of Pediatrics, State University of New York Downstate Medical Center, Box 49450 Clarkson Ave. Brooklyn, NY 11203, USA. Email: tamar.smithnorowitz@downstate.edu
In many countries, including in the Netherlands, screening for C. trachomatis is not part of routine antenatal care due to the lack of randomized controlled trial evidence that a screening program would be effective and subsequent cost-effectiveness studies that are needed for decision making. The only previous economic analysis for the Netherlands was hypothetical. ${ }^{6}$ Recently, we reported prevalence data and an association of chlamydial infection with chorioamnionitis and early premature delivery. ${ }^{7-9}$ The latter implies that screening may be more cost-effective than previously estimated.

In the absence of randomized controlled trial evidence, we estimate the cost-effectiveness of $C$. trachomatis screening in pregnant women in the Netherlands based on a static model using recent data from a population-based 


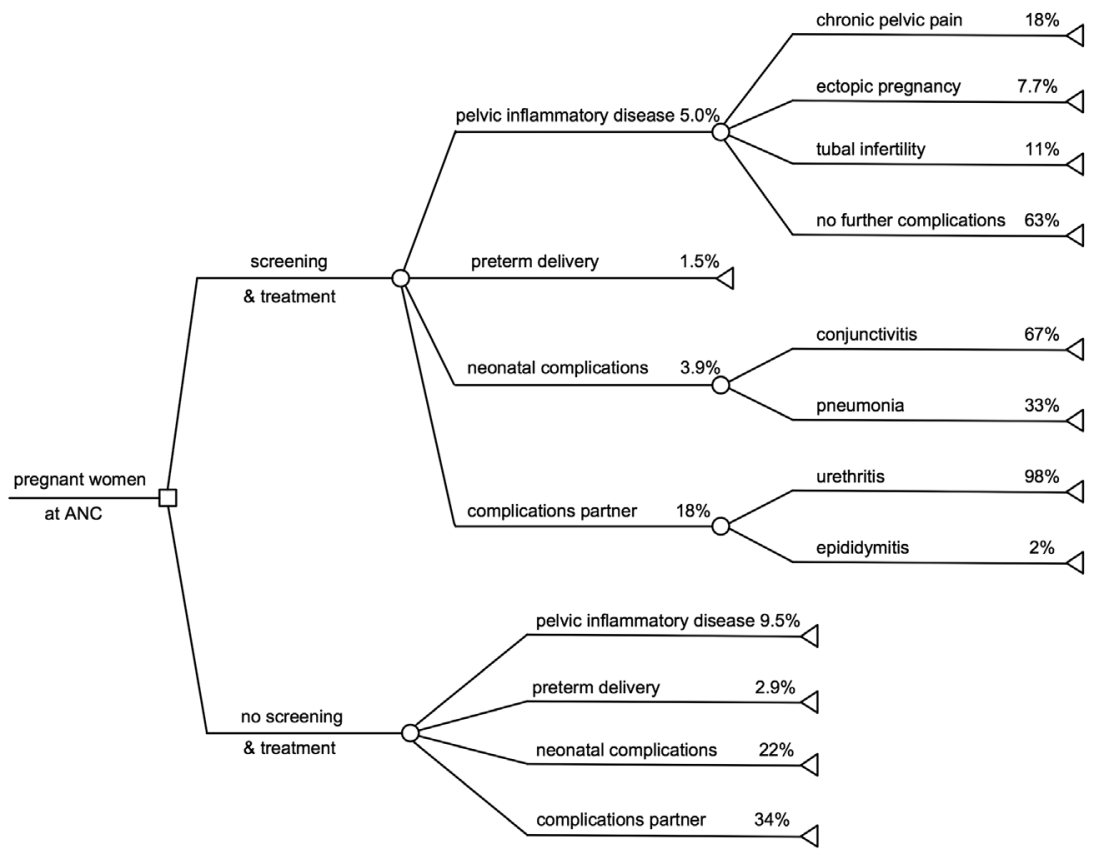

Figure 1 Decision tree study arms: Sample of decision tree displaying the two study arms, slightly modified: A scenario in which pregnant women are screened for chlamydia, and a scenario in which no screening program exists

prospective cohort study and a decision tree of complications that includes preterm delivery.

\section{Materials and methods General model design}

To analyze the cost-effectiveness of antenatal chlamydia screening, we used a medical decision tree linked to a static epidemiological model. The decision tree reflects progression of $C$. trachomatis infection in pregnant women in a screening and nonscreening scenario combining acute disease and long-term complications for women, pregnancy outcome, neonates and partners (Figure 1) (Appendix Figure A1, Table 1). The data and assumptions that we used reflect the context for pregnant women in the Netherlands (Appendix Tables A1 and B1). We analyzed screening to detect 1000 chlamydia-positive women. The number needed to screen with $3.9 \%$ prevalence would be 26,064 women.

\section{Epidemiologic data}

We used prevalence data from a prospective multicenter, population-based Chlamydia study among 4055 pregnant women in Rotterdam, of whom 95\% was included before 22 weeks gestation. ${ }^{8}, 10$ Pooled urine specimens obtained at the first antenatal visit were tested by NAAT. ${ }^{7}$ In total, 157 women $(3.9 \%)$ tested positive for $C$. trachomatis. Agespecific prevalences were $13.5 \%$ in women $<21$ years $(n=$ $251), 6.7 \%$ between $21-25$ years $(n=794), 3.3 \%$ between $26-30$ years $(n=1235)$, and $1.6 \%$ in women over 30 years of age $(n=1775)$ (Appendix Table A1). Pregnancy-specific prevalences were $4.5 \%$ in primigravida, 3.1 and $3.6 \%$ in women with a second or next pregnancy. Women were followed regarding pregnancy outcomes. Adverse outcomes such as miscarriage, low birth weight and perinatal death were not found to be associated with chlamydial infection. However, after adjustment for maternal age, ethnicity, gravidity and smoking, chlamydia-positive women had a 2.66-fold increased risk of premature delivery before 35 weeks gestation (Table 1).

We used figures with respect to maternal complications from previous international studies (Table 1). We obtained additional data regarding the outcome of premature delivery from the Perinatal Registry Netherlands (Appendix Table A1). ${ }^{11}$

\section{Risks, disease costs, and quality-adjusted life years}

In addition to symptomatic PID, chronic pelvic pain (CPP), ectopic pregnancy and infertility, neonatal conjunctivitis and pneumonia, and symptomatic male urethritis and epididymitis, we included preterm delivery in the decision tree and cost-effectiveness analysis (CEA) model (Appendix Figure A1, Table 1).

Since women were already pregnant and only a small proportion would acquire chlamydial infection on the same episode of intercourse that would result in pregnancy, probabilities for ectopic pregnancy and tubal infertility after (postpartum) PID were not included in the baseline scenario for the current pregnancy but only for a next pregnancy if this was expected to occur. The probability for a next pregnancy was based on Dutch data (www.cbs.nl) for having a second (78\%), third (50\%) or next pregnancy $(45 \%)$. In the sensitivity analysis we calculated for these pregnancy rates individually, which results were aggregated for the base-case analysis.

We assumed $100 \%$ aversion of neonatal infections if women were screened and treated since neonatal infection 


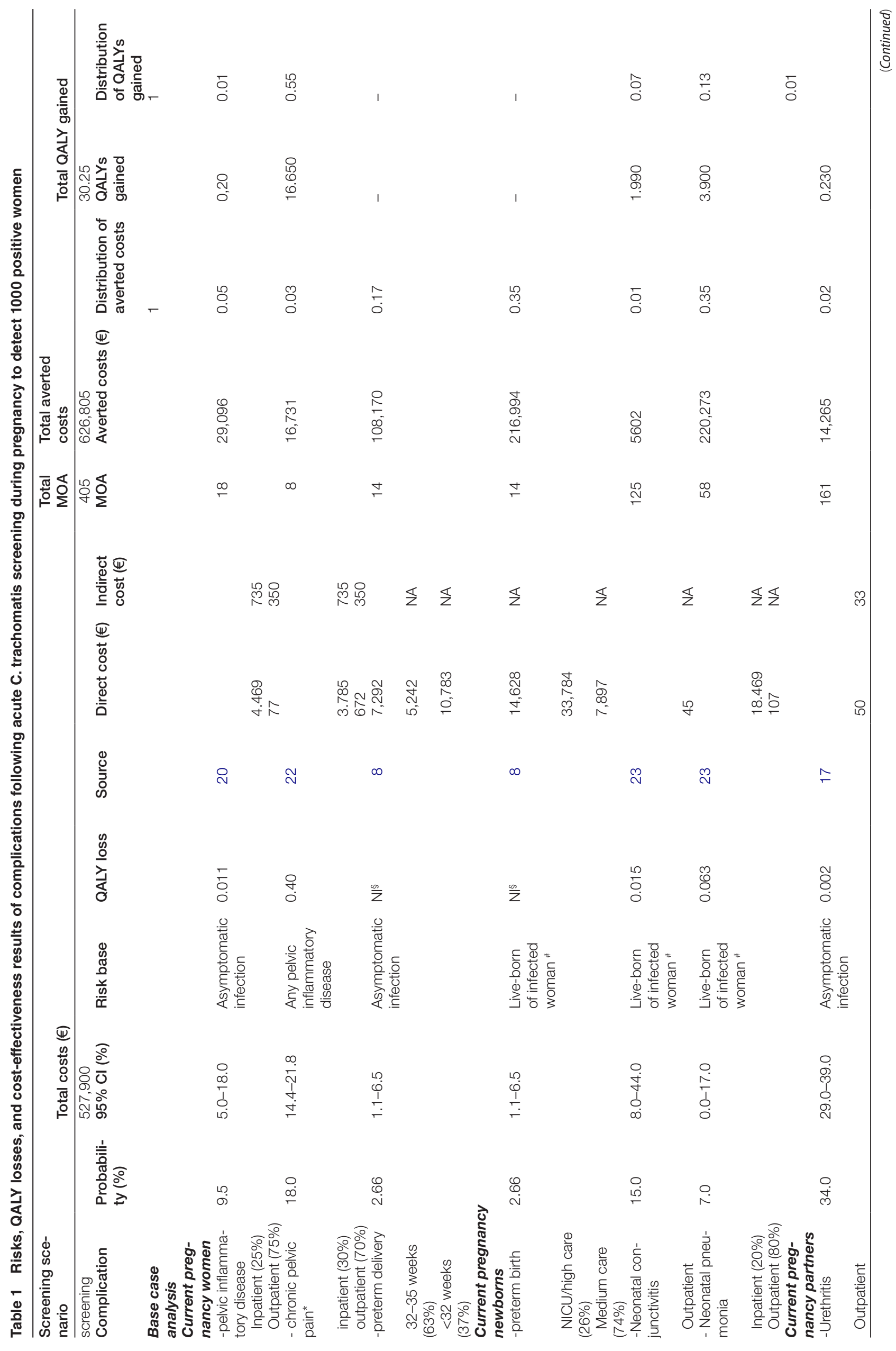




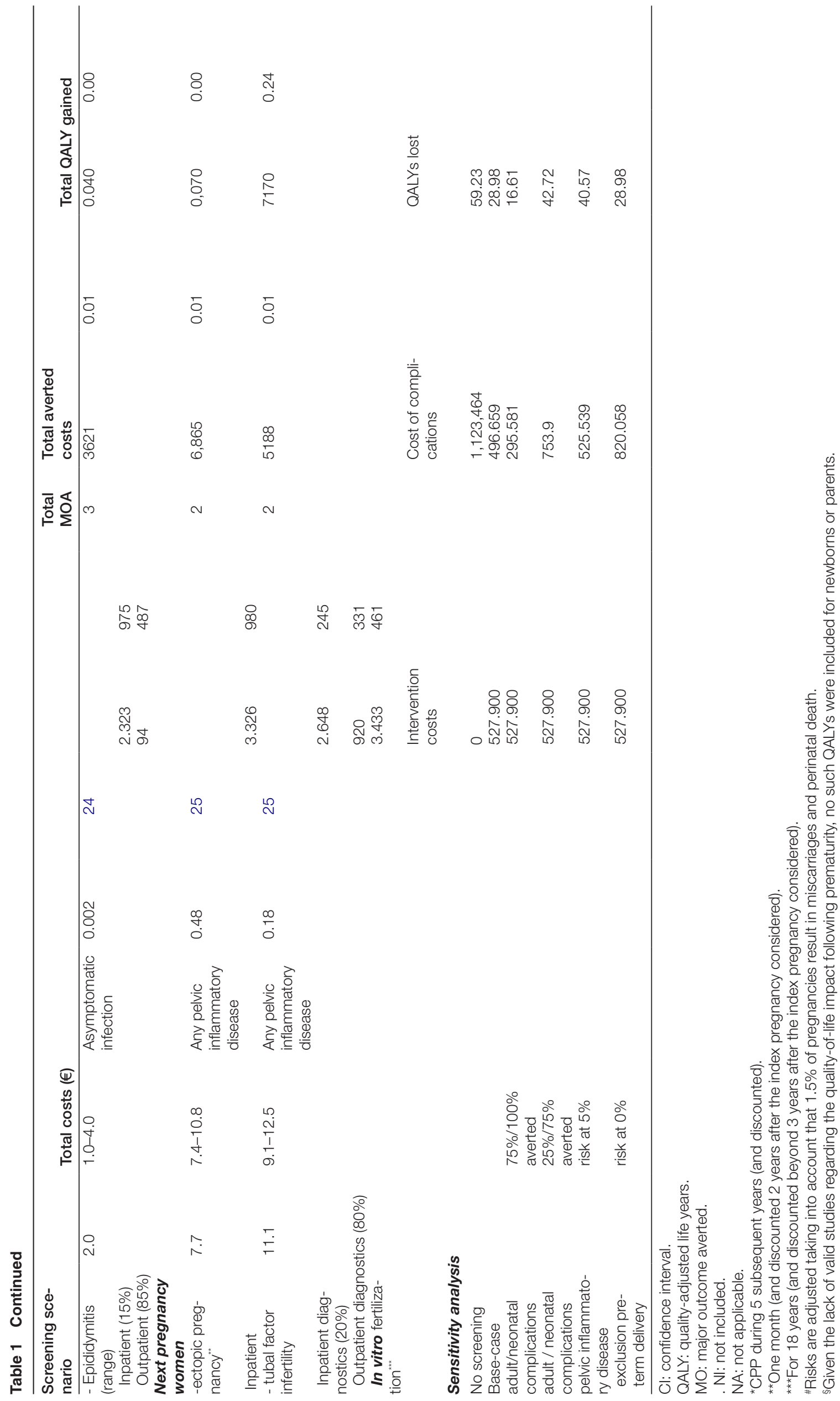


is directly related to maternal infection. We assumed 50\% reduction of all other complications since infection may already have caused irreversible damage. ${ }^{12}$ Crude percentages assumed for averting complications were corrected in case pharmacotherapy failed.

Reinfection due to the absence of partner treatment was not included in the analysis. We assumed that women and partners who were married or living in steady relationships would take medication concurrently and have no extra-relational sexual contact during the remainder of their pregnancy. For the remainder of the current pregnancy, a similar assumption was made for single women without a steady relationship. However, potential reinfection was included in case partner treatment failed with a probability of 22.3 per 100 person-years as previously reported for family planning clinics. ${ }^{13,14}$ Other input parameters and assumptions for probabilistic analysis are presented online (Appendix Table A1). ${ }^{15}$

Costs include direct medical costs of treatment for infection and complications, and indirect costs of production losses (Table 1). Previously, reported costs were updated using appropriate inflators to achieve 2009 price levels (www.cbs.nl). ${ }^{12}$ According to Dutch pharmacoeconomic guidelines we discounted the costs of CPP, ectopic pregnancy, and infertility at $4 \%$ per year taking on average 2.5 years between two pregnancies into account (www. cbs.nl). ${ }^{16}$ Other costs occurred in the year of analysis only and were not subjected to discounting. According to Dutch obstetric guidelines, premature deliveries are in general $(<35$ weeks) or academic hospitals ( $<32$ weeks).

Assumed quality-adjusted life year (QALY) losses are listed in Table $1 .{ }^{17,18}$ As for costs, QALY gains were similarly discounted according to Dutch standard practice at a rate of $1.5 \%$ per annum. ${ }^{16}$

\section{Intervention costs}

Intervention costs and model assumptions are presented online (Appendix Tables A1 and B1). We assumed screening to be incorporated in the existing routine antenatal care of testing for HIV, syphilis, and other infections. We included the use of NAATs to test urine specimens for C. trachomatis, because of the noninvasive nature of sampling, high sensitivity and specificity, and the possibility of pooled testing. ${ }^{7}$ Test costs were assumed at $€ 18$ (test price $€ 15$, overhead costs $€ 3$ ), which included discounts presumably achieved in large-scale use of tests as would be in a screening program (Appendix Table B1). If women tested positive, we assumed treatment by her regular health care provider. Partners would be referred to a General Practitioner. According to Dutch guidelines, we included azithromycin treatment for adults and erythromycin for infants.

\section{Cost-effectiveness analysis}

Risks, costs and QALY losses were linked within a static cost-effectiveness model. We calculated the cost-effectiveness ratio: $\mathrm{CER}=\left(\mathrm{C}_{\mathrm{S \& T}}-\mathrm{S}_{\mathrm{C}}\right) / \mathrm{QALY}$ gained, in which

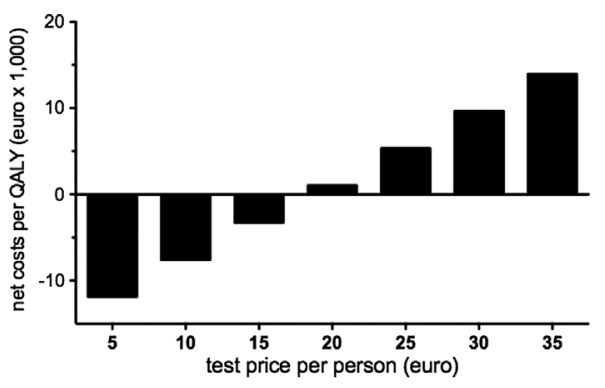

Figure 2 Sensitivity analysis. Sensitivity analysis of the test price demonstrated that net cost-savings remain as long as test costs are below $€ 22$ (break-even test costs); test price of $€ 19$

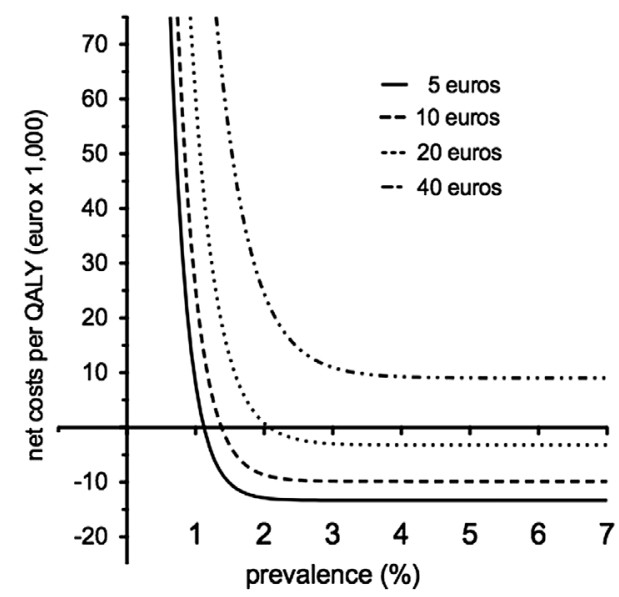

Figure 3 Costs per QALY gained for screening in pregnant populations with chlamydia prevalences. At $€ 18$ test costs (price €15) the results indicated net cost savings for screening populations with prevalences $\geq 3.2 \%$

costs for screening and treatment minus savings on complications are divided by QALY losses averted. These calculations were consistently done for various age groups and pregnancy rates. The analysis was performed from a societal perspective by inclusion of non-medical (indirect) costs due to production losses.

Calculations were performed in a base-case analysis, sensitivity, and scenario analysis. In the base-case analysis, we used the above-mentioned risks, assumptions, costs, QALYs, discount rates, and effectiveness of screening for all women. We explored uncertainty in the model using univariate sensitivity analysis to evaluate the impact of varying parameters; especially the ones previously published to be highly influential (PID), expected to be of major impact (percentage adult and neonatal complications averted, and preterm delivery), and the test price (Table 1, Figure 2). ${ }^{19,20}$ In addition, we performed a multivariate probabilistic sensitivity analysis, in which $95 \%$ confidence intervals were transformed into probability (beta) distributions. ${ }^{15}$ Finally, we performed a scenario analysis for possible target groups based on age (cutoffs at 20,25, and 30 years) and pregnancy rate (first, second, or next pregnancies), for discount rates (range 0-4\%) for 
costs and QALYs, and for costs of preterm birth since these may vary between countries. ${ }^{21}$

\section{Results \\ Base-case analysis}

In the base-case analysis, we estimated an investment of $€ 527,900$ to detect and treat $C$. trachomatis infection for 1000 pregnant women and their partners: $€ 469,100$ for initial testing and $€ 58,800$ for (partner) treatment and follow-up (Table 1). Averted medical costs were estimated at $€ 626,800$ with main savings due to prevention of preterm delivery, neonatal pneumonia and PID. Resulting net costs were negative indicating overall net cost-savings. In total, 405 complications would be averted and 30.25 QALYs would be gained per 1000 chlamydia-positive women detected (Table 1).

\section{Sensitivity analysis}

Sensitivity analysis of the test price demonstrated that net cost savings remain as long as test costs are below €22 (break-even test costs); test price of $€ 19$ (Figure 2)

Varying the proportion of averted adult $(25-75 \%)$ and neonatal (75-100\%) complications, rendered estimated costs less than $€ 10,000$ per QALY over the whole range for base-case test costs at $€ 18$. Break-even test costs were $€ 11$ and $€ 29$, respectively. Varying all individual risks for complications, including PID, rendered savings over the whole range for base-case test costs.

Results appeared most sensitive to preterm delivery. However, exclusion from the model still resulted in favorable cost-effectiveness in the base case at $€ 7400$ per QALY averted, break-even costs at $€ 9$, and the cost-effectiveness still $€ 9100$ and $€ 17,800$ per QALY gained for test costs at $€ 20$ and $€ 30$, respectively.

\section{Scenario analysis and probabilistic analysis}

CEA results may vary by prevalence in a given population, age and pregnancy rate.

For age-specific screening at $€ 18$, results indicated averted medical costs for women $\leq 20$ years (break-even test costs $>€ 35$ ), 21-25 years (break-even test costs $>€ 35$ ), and 26-30 years (break-even test costs $€ 18$; CER around $€ 20,000$ per QALY for test costs as high as €35). For women age $>30$ years, screening was still acceptable at $€ 18$; with $€ 21,000$ per QALY and break-even costs at $€ 8$.

Screening by pregnancy rate resulted in cost-savings or low CERs over the whole range. Break-even test costs were $€ 25$ for first pregnancies and $€ 17$ for second and next pregnancies. The CER for second and next pregnancies was $€ 6500-9100$ per QALY for test costs at $€ 25$.

Figure 3 shows the costs per QALY gained for screening in pregnant populations with chlamydia prevalences. At $€ 18$ test costs (price $€ 15$ ), the results indicated net cost savings for screening populations with prevalences $\geq 3.2 \%$. At the extremes, with a test price at $€ 10$ cost savings occurred at prevalences $\geq 2.3 \%$; at $€ 35$ cost savings occurred at prevalences $\geq 6.7 \%$. However, with $€ 35$, the cost-effectiveness was still below $€ 20,000$ per QALY gained for prevalences over 3.3\%.

If discount rates were multivariately ranged from $0 \%$ to $4 \%$ for both costs and QALYs, cost-savings remained at base-case test costs. At $€ 35$, cost-effectiveness worsened slightly from $€ 11,000$, when discounting costs at $4 \%$ and QALYs at $1.5 \%$ according to Dutch guidelines, to $€ 12,000$, when discounting both at $4 \%$.

Probabilistic analysis showed that of 1000 simulations performed, $48 \%$ indicated cost-savings in the base case and over $95 \%$ was less than $€ 17,000$ per QALY gained. Using a lower estimate (50\%) for the costs of neonatal hospitalization, probabilistic analysis still showed cost savings in $30 \%$ of simulations and $95 \%$ less than $€ 18,000$ per QALY gained.

\section{Discussion}

The present health-economic analysis shows that screening for C. trachomatis would be cost saving if all pregnant women would be included in a screening program in the Netherlands at a test price up to $€ 20$. Sensitivity analysis shows that screening remains cost saving if relevant parameters such as test price and complication rates are varied and favorable cost-effectiveness if preterm delivery is excluded. Scenario analysis shows that health-economic gain can be even further increased if screening would aim at women below 30 years or women with first pregnancies only.

Pregnant women are a specific target group for C. trachomatis screening. Antenatal screening, as recommended in several countries, would be beneficial to decrease morbidity among women themselves and to prevent vertical and horizontal transmission. ${ }^{26,27}$ At present, seven of 25 European Union member states included chlamydia screening in their antenatal guidelines for normal pregnancies, ${ }^{28}$ but not the Netherlands, and many other countries, due to the lack of randomized clinical trial evidence and a subsequent cost-effectiveness analysis. Recent findings of a chlamydial prevalence of 3.9\% among Dutch pregnant women, an association with chorioamnionitis and increased risk of preterm delivery lead us to perform a CEA for the Netherlands. ${ }^{8,9}$ We think that these results may also be of interest for other (European) countries. Starting point of our CEA is that screening would be incorporated in the already existing routine of antenatal care as can be done in most countries. A major advantage is that, in contrast to screening in a general population, women will visit an antenatal clinic seeking health care for their unborn and themselves, which is a good opportunity to offer screening that enhances participation dramatically: $90 \%$ v. $37 \% .^{8,29}$

It should be mentioned that in the current CEA, we included data on preterm delivery. We acknowledge that evidence on complication probabilities is conflicting and that there is no consensus in the medical community regarding an association between chlamydial infection 
and premature delivery; previous conflicting reports were mainly due to differences in study design, population and also the test methods that were being used ${ }^{30}$. Studies of others didn't take preterm delivery into account. ${ }^{6,12,13,31-34}$

To our knowledge, chlamydial infection has been associated with preterm delivery in seroepidemiologic studies, although this is not a consistent finding. ${ }^{35-37}$

However, the more recent studies among pregnant women that are using NAATs to diagnose $C$. trachomatis infection also demonstrated an association with preterm delivery. ${ }^{3-5}$ Prior literature has found no association with preterm delivery; women had already been tested and treated for infection before 29 weeks gestation. ${ }^{38,39}$ Another reason our study group included PTD into the current analysis was that the association of chlamydial infection with PTD in the prospective study among 4055 pregnant Dutch women was supported by another independent study of $C$. trachomatis infection in placentas of 304 pregnant women who all delivered before 32 weeks gestation ${ }^{40}$ Based on the findings in both studies and many other recent studies, we included preterm delivery in our analysis..$^{1-5,8}$

We chose a static model for analysis instead of a dynamic model. Dynamic models include explicitly transmission dynamics in a population, i.e. 'a force of infection that varies' with changing population prevalences. ${ }^{12,17,41}$ Screening decreases the prevalence and subsequently lowers the probability to encounter an infected partner and indirectly protects for future sex partners. Dynamic models are especially warranted to screen populations with frequently changing sexual partners. ${ }^{42}$ Static models, on the contrary, include 'a constant force of infection' or constant probability to encounter an infected partner. These include only cures that are directly related to screening and treatment, but not to changing prevalences or risks due to averted infections. Static models suffice to assess populations in which frequent change of sexual partners is not common. ${ }^{43}$ We chose a static model approach, because absence of frequently changing sexual partners may be a reasonable assumption in steady relationships with pregnancy in the Netherlands; especially after women and partners having learned about the risks of chlamydial infection for mother and child as this information would be provided during a screening program. Also, we assumed that partners would be treated at the same time and would, having learned about the risks of infection, take responsibility for their partner and offspring. Hence, screening and treatment of pregnant women would not have a major effect on the pool of carriers within the total population or on subsequent birth cohorts at risk. We included a lower probability of being infected in a next pregnancy, though, since this would be likely with the same partner.

A major challenge of our cost-effectiveness analysis, compared to a cost-benefit analysis, is that besides the epidemiologic data, also QALYs need to be incorporated. We tried to carefully select - in our opinion most likely evidence. However, epidemiologic data are population-specific. And when data do not exist reasonable assumptions have to be made. This may cause uncertainties as does the inclusion of QALYs. We used QALYs from the literature, but excluded the loss due to asymptomatic PID and preterm delivery. For the latter, we did not find a figure, but the QALY loss form preterm delivery will undoubtedly be high. To mitigate the effect that uncertainties may have on the final results, we performed in-depth sensitivity analyses to provide a sense of how outcomes may change given different values for different populations should the true value of given variables be greater or less than those used in our model.

In the sensitivity analysis, we varied the parameters that drive our model. Preterm delivery increased the public healthcare costs dramatically. However, after exclusion of preterm delivery to make the model comparable to previous CEA, screening still showed acceptable cost-effectiveness at $€ 7400$ per QALY gained with break-even test costs at $€ 9$. Cost savings in the base case remained with test costs up to $€ 22$, low risks of PID or varying any other parameter within confidence intervals.

We demonstrated that the benefits of averted direct and indirect costs are much higher than investment costs for incorporating chlamydia screening into routine antenatal care despite the otherwise conservative approach we used. Advantages of incorporating screening in routine care are that expensive investment costs are relatively low because the infrastructure, logistics, most equipment and personnel are already present. Further, we worked, apart from $100 \%$ aversion of neonatal infections, with only $50 \%$ of all other complications being avertable. We also did not include costs or QALY losses for side-effects of treatment such as pyloric stenosis. ${ }^{23}$ Furthermore, we did not include potentially high costs of long-term complications due to premature birth such as lifelong disability or handicap, neuromotor dysfunction and mental development, musculoskeletal and respiratory complications. We did not calculate extra costs and production losses for parents of premature newborns directly after birth and following years or potential production losses of prematurely born individuals themselves during their lives. In addition, we did not include QALY losses due to premature birth for infants and parents since we did not have such recent data, which clearly underestimates the true total QALY loss. On the other hand, we did not include QALY losses due to false-positive results, which may lead to lost trust within a relationship. Despite our approach, both base-case analysis and sensitivity analysis demonstrated that screening would be cost saving. While varying the proportion of averted complications to lowest levels, cost-effectiveness remained below $€ 20,000$ per QALY; also with higher than base-case test prices. Even, after lowering the costs for NICU admission to almost $50 \%$ as previously reported, cost-effectiveness remained below $€ 2000$ per QALY. ${ }^{21}$ In the Netherlands, cost-effectiveness below $€ 20,000$ per QALY gained is informally taken as a threshold for 
accepting preventive programs from a health-economic point of view, but up to $€ 50,000$ per QALY has been argued to still reflect acceptable cost-effectiveness.

Our results demonstrate that screening for C. trachomatis in the Netherlands would be cost saving if screening would be based on pregnancy rate or age if assuming higher than base-case test prices, except for screening women over 30 years of age. However, the latter would still be considered acceptably cost-effective in the Netherlands.

Extrapolating our CEA to all pregnant women in the Netherlands, approximately 175,000 pregnancies per year, the total costs for $C$. trachomatis screening and treatment could be estimated at $€ 3,544,500$ annually with a counterbalance by cost savings of $€ 4,208,600$. This means that antenatal chlamydia screening would lead to net savings of more than almost half a million euro each year in addition to more than 200 QALYs gained. We think our results may be generalizable to other (European) countries, although CEA may have to be recalculated with other costs related to prematurity, which obviously differ per country.

Previous studies in our laboratory examined incidence and treatment outcomes of chlamydial conjunctivitis in the prescreening era. ${ }^{44}$ Hammerschlag et al ${ }^{44}$ reported that prenatal screening and treatment of pregnant women was the most effective way to prevent neonatal chlamydial infections, especially as neonatal ocular prophylaxis has not been demonstrated to be effective in prevention of neonatal chlamydia conjunctivitis. ${ }^{44}$ These results offer support for the importance of a screening program by reducing neonatal chlamydia-associated morbidity ${ }^{39}$. +Rours; South Afr J Epidemol Infect 2006; vol $21^{1}$

Ong et $a l .{ }^{45}$, in a study from Australia, found that antenatal screening of women aged 16-25 is likely to be cost-effective with significantly reduced morbidity. The findings from our current decision analysis model are in agreement with the aforementioned studies. Ong et al. reported prevalence rates that were gathered from Australian family planning clinic records, and vertical transmission data was gathered from previously published studies in other populations. ${ }^{45}$ Despite this, another recent study found that only fourteen countries have policies for antenatal C. trachomatis screening; with the Middle East, Central American and South America void of countries that following WHO screening guidelines for antenatal screening. ${ }^{46}$

\section{Conclusions}

Based on currently available data we conclude that screening all pregnant women for C. trachomatis is cost saving in the Netherlands and that screening aimed at women less than 30 years or with first pregnancies only further increases savings. A randomized clinical trial regarding the inclusion of a C. trachomatis screening intervention into routine antenatal care is recommended to provide best evidence for the effect of screening on maternal and neonatal health as well as on pregnancy outcome.

\section{Conclict of interest}

The authors declare no conflict of interest to disclose.

\section{Funding}

The authors have no competing financial interest to disclose.

\section{References}

1 Cohen I, Veille JC, Calkins BM. Improved pregnancy outcome following successful treatment of chlamydial infection. J Am Med Assoc. 1990;263(23):3160-3.

2 Rastogi S, Das B, Salhan S, Mittal A. Effect of treatment for Chlamydia trachomatis during pregnancy. Int J Gynaecol Obstet. 2003;80(2):129-137.

3 Andrews WW, Goldenberg RL, Mercer B, Iams J, Meis P, Moawad A, et al. The preterm prediction study: association of second-trimester genitourinary chlamydia infection with subsequent spontaneous preterm birth. Am J Obstet Gynecol. 2000;183(3):662-668.

4 Odendaal HJ, Schoeman J. The association between Chlamydia trachomatis genital infection and spontaneous preterm labour. S Afr J Obstet Gynaecol. 2006;12(3):146-149.

5 Blas MM, Canchihuaman FA, Alva IE, Hawes SE. Pregnancy outcomes in women infected with Chlamydia trachomatis: a population-based cohort study in Washington State. Sex Transm Infect. 2007;83(4):314-318.

6 Postma MJ, Bakker A, Welte R, van Bergen JE, Van den Hoek JA, de Jong-van den Berg LT, et al. Screening for asymptomatic Chlamydia trachomatis infection in pregnancy; cost-effectiveness favorable at a minimum prevalence rate of $3 \%$ or more. Ned Tijdschr Geneeskd. 2000;144(49):2350-2354.

7 Rours GIJG, Verkooyen RP, Willemse HF, van der Zwaan EA, van Belkum A, de Groot R, et al. Use of pooled urine samples and automated DNA isolation to achieve improved sensitivity and costeffectiveness of large-scale testing for Chlamydia trachomatis in pregnant women. J Clin Microbiol. 2005;43(9):4684-4690.

8 Rours GI, Duijts L, Moll HA, et al. Chlamydia trachomatis infection during pregnancy associated with preterm delivery: a populationbased prospective cohort study. Eur J Epidemiol. 2011;26(6):493-502.

9 Rours GI, de Krijger RR, Ott A, et al. Chlamydia trachomatis and placental inflammation in early preterm delivery. Eur J Epidemiol. 2011;26(5):421-428.

10 Jaddoe VW, van Duijn CM, van der Heijden AJ, et al. The generation R study: design and cohort update until the age of 4 years. Eur J Epidemiol. 2008;23(12):801-811.

11 The Netherlands Perinatal Registry. Perinatal care in the Netherlands 2008. Utrecht: Stichting Perinatale Registratie Nederland; 2011.

12 de Vries R, van Bergen JE, de Jong-van den Berg, et al. Systematic screening for Chlamydia trachomatis: estimating cost-effectiveness using dynamic modeling and Dutch data. Value Health. 2006;9(1):111.

13 Postma MJ, Welte R, van den Hoek JA, et al. Cost-effectiveness of partner pharmacotherapy in screening women for asymptomatic infection with Chlamydia trachomatis. Value Health. 2001;4(3):266275.

14 Scott LaMontagne D, Baster K, Emmett L, Nichols T, Randall S, McLean L, et al. Incidence and reinfection rates of genital chlamydial infection among women aged 16-24 years attending general practice, family planning and genitourinary medicine clinics in England: a prospective cohort study by the Chlamydia recall study advisory group. Sex Transm Infect. [Multicenter Study Research Support, Non-U.S. Gov’t]. 2007;83(4):292-303.

15 Briggs AH. Handling uncertainty in economic evaluation and presenting the results. In: Drummond M, McGuire A, editors. Economic evaluation in health care. Merging theory and practice. New York: Oxford University Press; 2001;172-214.

16 Riteco JA, de Heij LJM, Luijn JCF, Wolff IR. Guidelines for pharmacoeconomic research (in Dutch: Richtlijnen Voor Farmacoeconomisch Onderzoek). Amstelveen: College voor Zorgverzekeringen; 1999.

17 de Vries R, van Bergen JE, de Jong-van den Berg LT, Postma MJ. Cost-utility of repeated screening for Chlamydia trachomatis. Value Health. 2008;11(2):272-274.

18 Coyne KS, Payne C, Bhattacharyya SK, Revicki DA, Thompson C, Corey R, et al. The impact of urinary urgency and frequency on healthrelated quality of life in overactive bladder: results from a national community survey. Value Health. 2004;7(4):455-463. 
19 van Valkengoed IG, Morre SA, van den BruleAJ, Meijer CJ, Bouter LM, Boeke AJ. Overestimation of complication rates in evaluations of Chlamydia trachomatis screening programmes-implications for costeffectiveness analyses. Int J Epidemiol. 2004;33(2):416-425.

20 Oakeshott P, Kerry S, Aghaizu A, et al. Randomised controlled trial of screening for Chlamydia trachomatis to prevent pelvic inflammatory disease: the POPI (prevention of pelvic infection) trial. BMJ. [Multicenter Study Randomized Controlled Trial Research Support, Non-U.S. Gov't]. 2010;340:c1642

21 Kekki M, Kurki T, Kotomaki T, Sintonen H, Paavonen J. Costeffectiveness of screening and treatment for bacterial vaginosis in early pregnancy among women at low risk for preterm birth. Acta Obstet Gynecol Scand. [Research Support, Non-U.S. Gov't]. 2004;83(1):27-36.

22 Weström L. Effect of acute pelvic inflammatory disease on fertility. Am J Obstet Gynecol. 1975;121(5):707-713.

23 Rosenman MB, Mahon BE, Downs SM, Kleiman MB. Oral erythromycin prophylaxis vs watchful waiting in caring for newborns exposed to Chlamydia trachomatis. Arch Pediatr Adolesc Med. 2003;157(6):565-571.

24 Gillespie P, O’Neill C, Adams E, Turner K, O’Donovan D, Brugha $\mathrm{R}$, et al. The cost and cost-effectiveness of opportunistic screening for Chlamydia trachomatis in Ireland. Sex Transm Infect. 2012;88(3):222-228.

25 Weström L, Joesoef R, Reynolds G, Hagdu A, Thompson SE. Pelvic inflammatory disease and fertility. A cohort study of 1844 women with laparoscopically verified disease and 657 control women with normal laparoscopic results. Sex Transm Dis. 1992;19(4):185-192.

26 Centers for Disease Control and Prevention. 2015 Sexually transmitted diseases treatment guidelines. MMWR Recomm Rep 2015;64(No. RR-3):1-140.

27 U.S. Preventive Services Task Force. Screening for Chlamydial infection: U.S. preventive services task force recommendation statement. Ann Intern Med. 2007;147(2):128-134.

28 Bernloehr A, Smith P, Vydelingum V. Antenatal care in the European Union: a survey on guidelines in all 25 member states of the community. Eur J Obstet Gynecol Reprod Biol. 2005;122(1):22-32.

29 van Bergen J, Gotz HM, Richardus JH, Hoebe CJ, Broer J, Coenen AJ. Prevalence of urogenital Chlamydia trachomatis increases significantly with level of urbanisation and suggests targeted screening approaches: results from the first national population based study in the Netherlands. Sex Transm Infect. 2005;81(1):17-23.

30 Price MJ, Ades AE, Soldan K, Welton NJ, Macleod J, Simms I, et al. The natural history of Chlamydia trachomatis infetion in women: a multi parameter evidence synthesis. Health Technol Assess. 2016;20:1-250.

31 Marrazzo JM, Celum CL, Hillis SD, Fine D, DeLisle S, Handsfield HH. Performance and cost-effectiveness of selective screening criteria for Chlamydia trachomatis infection in women. Implications for a national Chlamydia control strategy. Sex Transm Dis. 1997;24(3):131-141.

32 Howell MR, Quinn TC, Gaydos CA. Screening for Chlamydia trachomatis in asymptomatic women attending family planning clinics: a cost-effectiveness analysis of three strategies. Ann Intern Med. 1998;128(4):277-284.
33 Roberts TE, Robinson S, Barton PM, et al. Cost effectiveness of home based population screening for Chlamydia trachomatis in the UK: economic evaluation of chlamydia screening studies (ClaSS) project. BMJ. 2007;335(7614):291.

34 Adams EJ, Turner KM, Edmunds WJ. The cost effectiveness of opportunistic chlamydia screening in England. Sex Transm Infect. 2007;83(4):267-275.

35 Ramos-Zepeda R, Perez-Medina R, Barba-Barajas M,Palma-RamirezT, Flores-Garcia A, Garibaldi -Becerra V, et al. Chlamydia trachomatis infection in pregnant women with premature membrane rupture or premature delivery threat. Rev Biomed. 2001;12:158-165.

36 Claman P, Toye B, Peeling RW, Jessamine P, Belclher J Serologic evidence of Chlamydia trachomatis infection and risk of preterm birth. Can Med Assoc J. 1995;153:259-262.

37 Gencay MI, Koskiniemi M, Saikku P, Puolakkainen M, Raivio K, Koskela P, et al. Chlamydia trachomatis seropositivity during pregnancy is associated with perinatal complications. Clin Infect Dis. 1995;21:424-426.

38 Kataoka S, Yamada T, Chou K, Nishida R, Morikawa M, Minami M, et al. Association between preterm birth and vaginal colonization by mycoplasmas in early pregnancy. J Clin Microbiol. 2006;44(1):51-55.

39 Silveira MF, Ghanem KG, Erbelding EJ, Burke AE, Johnson HL, Singh RH. Chlamydia trachomatis infection during pregnancy and the risk of preterm birth: a case-control study. Int J STD AIDS. 2009;20(7):465-469.

40 Donders GG, Moerman P, De Wet GH, Hooft P, Goubau P. The asscociation between Chlamydia cervicitis, chorioamnionitis, and neonatal complications. Arch Gynecol Obstet. 1991;249:79-85.

41 Kretzschmar M, Welte R, van den Hoek A, Postma MJ. Comparative model-based analysis of screening programs for Chlamydia trachomatis infections. Am J Epidemiol. 2001;153(1):90-101.

42 Welte R, Postma M, Leidl R, Kretzschmar M. Costs and effects of chlamydial screening: dynamic versus static modeling. Sex Transm Dis. 2005;32(8):474-483.

43 Quinn TC, Gaydos C, Shepherd M, Bobo L, Hook EW. Epidemiologic and microbiologic correlates of Chlamydia trachomatis infection in sexual partnerships. J Am Med Assoc. 1996;276(21):1737-1742.

44 Hammerschlag MR, Cummings C, Roblin PM, Williams TH, Delke I Efficacy of neonatal ocular prophylaxis for the prevention of chlamydial and gonococcal conjunctivitis. N Engl J Med. 1989;320(12):769-772.

45 Ong JJ, Chen M, Hocking J, Fairley CK, Carter R, Bulfone L, et al. Chlamydia screening for pregnant women aged 16-25 years attending an antenatal service: a cost-effectiveness study. Br J Obstet Gynaecol 2015: DOI:10.1111/1471-0528.13567.

46 Medline A, Joseph DD, Klausner JD. Lost opportunity to save newborn lives: variable national antenatal screening policies for Neisseria gonorrhoeae and Chlamydia trachomatis. Int J STD AIDS 2016 Jul 16. pii: 0956462416660483. Epub ahead of print. 


\section{Appendix:}

Figure A1 Medical decision tree for C. trachomatis screening during pregnancy based on complications in women, partners, and newborns

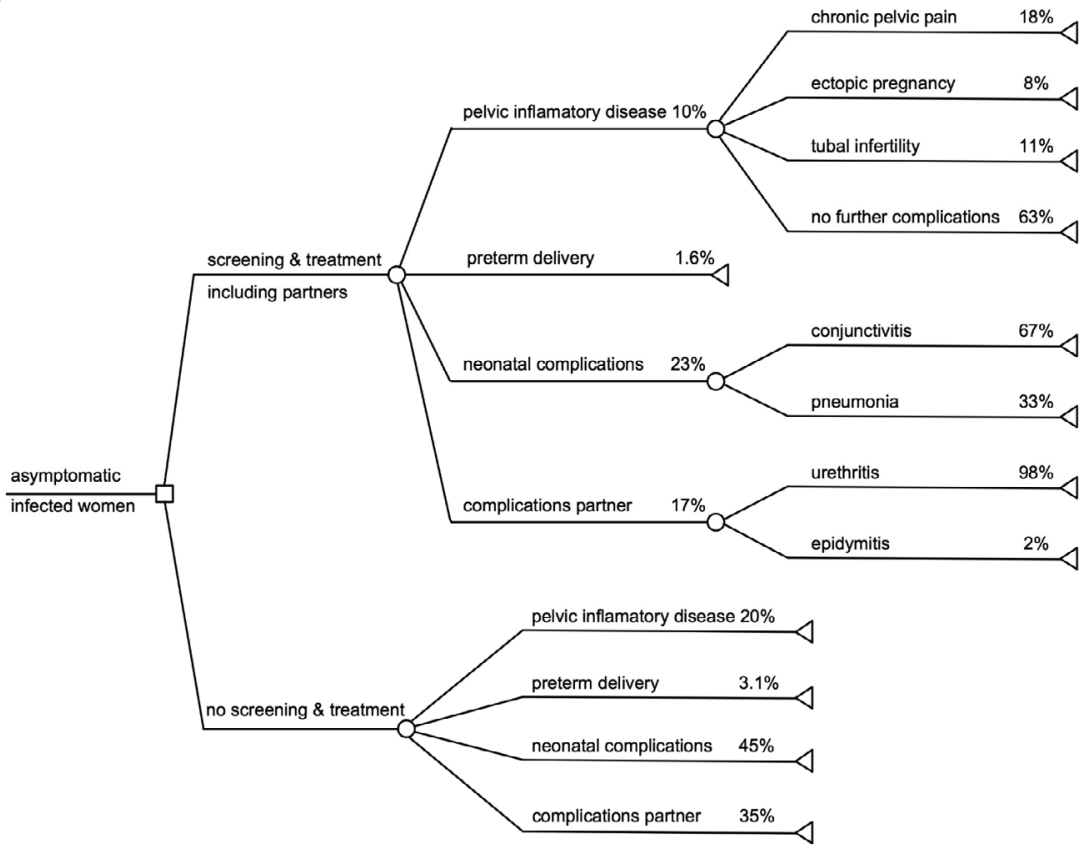

*For ease of presentation, the following outcomes are not shown in the tree: no PID as well as no CPP, no ectopic pregnancy, no tubal infertility; no preterm delivery; no neonatal complications as well as no conjunctivitis and no pneumonia; no complications in partner as well as no urethritis and no epididymitis.

${ }^{*}$ Percentages may add up over 100\% since complications can be in different individuals (pregnant women, newborns, and partners).

Table A1 Input parameter values for base-case and sensitivity analysis in the static model for C. trachomatis screening among pregnant women

\begin{tabular}{|c|c|c|c|}
\hline \multirow[b]{2}{*}{ Input parameter } & $\begin{array}{l}\text { Base-case } \\
\text { analysis }\end{array}$ & $\begin{array}{l}\text { Sensitivity } \\
\text { analysis }\end{array}$ & \multirow[t]{2}{*}{ Source } \\
\hline & $\begin{array}{l}\text { Probability } \\
\text { (\%) }\end{array}$ & $95 \% \mathrm{Cl}(\%)$ & \\
\hline Overall prevalence & 3.9 & $3.3-4.5$ & Rours, Europ J Epidemiol, $2011^{8}$ \\
\hline Prevalence $<21$ years & 13.5 & $9.6-18.4$ & Rours, Europ J Epidemiol, $2011^{8}$ \\
\hline Prevalence $21-25$ years & 6.7 & $5.0-8.6$ & Rours, Europ J Epidemiol, $2011^{8}$ \\
\hline Prevalence $26-30$ years & 3.3 & $2.4-4.5$ & Rours, Europ J Epidemiol, $2011^{8}$ \\
\hline Prevalence $>30$ years & 1.6 & $1.1-2.3$ & Rours, Europ J Epidemiol, $2011^{8}$ \\
\hline Female attendance antenatal clinic* ${ }^{\star}$ & 100 & - & SPNR $2008^{11}$ \\
\hline Health care provider offer rate ${ }^{\star \star}$ & 95 & $90-100$ & assumption, Rours, Europ J Epidemiol, $2011^{8}$ \\
\hline Female acceptance test ${ }^{\star \star}$ & 95 & $90-100$ & assumption, Rours, Europ J Epidemiol, $2011^{8}$ \\
\hline Test sensitivity, specificity & 100 & - & assumption, Gillespie ${ }^{24}$ \\
\hline Concordance partner infection & 68 & $58-78$ & Quinn, JAMA, $1996^{38}$ \\
\hline Effectiveness treatment women and men & 95 & $90-100$ & Gillespie, Sex Transm Inf, 2012, Stamm $1999^{24}$ \\
\hline Effective partner notification and treatment ${ }^{\star \star \star}$ & 95 & $90-100$ & assumption \\
\hline $\begin{array}{l}\text { Reinfection rate women (mean per } 100 \text { per- } \\
\text { son years) }\end{array}$ & 22.3 & $15.6-31.8$ & $\begin{array}{l}\text { Scott LaMontagne D, et al. Sex Transm Infect 2007, doi: } \\
\text { 10.1136/sti.2006.022053.14 }\end{array}$ \\
\hline $\begin{array}{l}\text { Offer retest to women after treatment in cur- } \\
\text { rent pregnancy }\end{array}$ & 100 & - & assumption \\
\hline Female acceptance retest & 100 & - & assumption \\
\hline Effectiveness treatment infants & 85 & 80-91 & Rosenman, Arch Pediatr adolesc med, $2003^{23}$ \\
\hline $\begin{array}{l}\text { Hospitalization rate among infants with } \\
\text { Chlamydial pneumonia }\end{array}$ & 50 & $20-80$ & assumption, de Vries ${ }^{23}$ \\
\hline $\begin{array}{l}\text { Hospitalization rate among Prema- } \\
\text { tures }<35 \text { weeks }\end{array}$ & 100 & - & Dutch guidelines \\
\hline Total number prematures $<35$ weeks & 9243 & - & SPNR $2008^{11}$ \\
\hline Total number prematures $<35$ weeks in $\mathrm{NICU}$ & 2434 & - & SPNR $2008^{11}$ \\
\hline $\begin{array}{l}\text { NICU admission rate among Prema- } \\
\text { tures }<35 \text { weeks }(2434 / 9243) \# \#\end{array}$ & 26 & - & SPNR $2008^{11}$ \\
\hline $\begin{array}{l}\text { Perifere admission rate medium } \\
\text { care }<35 \text { weeks\#\# }\end{array}$ & 74 & - & SPNR $2008^{11}$ \\
\hline
\end{tabular}


Table A1. (Continued)

\begin{tabular}{lccc}
\hline & $\begin{array}{c}\text { Base-case } \\
\text { analysis }\end{array}$ & $\begin{array}{c}\text { Sensitivity } \\
\text { analysis }\end{array}$ & Source \\
\cline { 2 - 4 } Input parameter & $\begin{array}{c}\text { Probability } \\
(\%)\end{array}$ & $95 \% \mathrm{Cl}(\%)$ & \\
\hline $\begin{array}{l}\text { Mean number ICU of NICU days per neonate } \\
(34,303 / 2434) \# \#\end{array}$ & 14.1 & - & SPNR 2008 \\
$\begin{array}{l}\text { Mean number high care of NICU per neonate } \\
(15,723 / 2434) \# \#\end{array}$ & 6.5 & - & SPNR 2008 \\
\end{tabular}

*We included $100 \%$ antenatal care attendance as is common in the Netherlands, which is mainly provided by midwives.

${ }^{*}$ We included a $95 \%$ offer rate due to unforeseen circumstances and $95 \%$ acceptance because of refusal due to psychosocial reasons or a priori reluctance to antibiotic treatment.

${ }^{* *}$ We included an effective partner notification and treatment rate of $95 \%$ since most women were living in steady partnerships and otherwise it is likely that women would be able to contact the biological father or provide contact details. ${ }^{8}$

"We assumed 100\% retesting during pregnancy since women had no objections for initial testing and might want certainty regarding clearance of infection.

\# We included the increased risk of preterm delivery as found previously and included national data regarding hospitalization rate and mean number of days admitted to a NICU for premature neonates less 35 weeks gestation (Appendix Table A1). ${ }^{8,11}$

Table B1 Costs related to $C$. trachomatis screening among pregnant women

\begin{tabular}{|c|c|c|c|c|}
\hline Resource category & Resource item & Unit/measure & Unit cost $(€)$ & Source \\
\hline \multirow[t]{6}{*}{ Overhead costs (total = 3,05) } & Personnel & Per screen & 2.65 & Study accounts \\
\hline & Telephone charges & Per screen & 0.05 & Study accounts \\
\hline & Computer equipment & Per screen & 0.10 & Study accounts \\
\hline & Stationary & Per screen & 0.10 & Study accounts \\
\hline & Printing & Per screen & 0.05 & Study accounts \\
\hline & Travel expenses & Per screen & 0.10 & Study accounts \\
\hline \multirow[t]{8}{*}{ Test offer/testing (total $=14,89$ ) } & Midwife time & $6.68 \mathrm{~min}$ & $-{ }^{*}$ & KNOV \\
\hline & Information brochure & Per screen & 0.02 & Study accounts \\
\hline & Consent form & Per screen & 0.01 & Study accounts \\
\hline & Request form & Per screen & 0.01 & LFI \\
\hline & Laboratory test & Per screen & 13.55 & Rours, 2011 \\
\hline & Laboratory personell & Per screen & 0.60 & LFI \\
\hline & Sample container & Per screen & 0.20 & LFI \\
\hline & Transport & Per screen & 0.50 & LFI \\
\hline \multirow[t]{2}{*}{ Diagnosis \& treatment } & Midwife time & $8.67 \mathrm{~min}$ & $-^{*}$ & KNOV \\
\hline & Azithromycin & Per dose & 1.04 & www.medicijnkosten.nl \\
\hline Retesting & $100 \%$ of positive women & Per consult & 14.86 & Study accounts \\
\hline \multirow[t]{3}{*}{ Partner test \& treatment } & GP time & Per visit & 21.4 & CVZ \\
\hline & Information brochure & Per screen & 0.01 & Study accounts \\
\hline & azithromycin & Per dose & 1.04 & www.medicijnkosten.nl \\
\hline \multirow[t]{3}{*}{ Hospitalization newborns ${ }^{\star *}$} & $\mathrm{NICU}<32$ weeks & Per day $\mathrm{AH}$ & 1.882 & Erasmus MC \\
\hline & High care $<32$ weeks & Per day $\mathrm{AH}$ & 1.115 & Erasmus MC \\
\hline & MC 32-35 weeks GA & Per admission GH & 7.897 & Maasstad Hospital \\
\hline \multirow[t]{2}{*}{ Hospitalization women ${ }^{\star \star}$} & $<32$ weeks GA & Per admission $\mathrm{AH}$ & 10.783 & Erasmus MC \\
\hline & 32-35 weeks GA & Per admission GH & 5.242 & Maasstad Hospital \\
\hline
\end{tabular}

Notes: KNOV: Royal Dutch Organization of Midwives, LFI: laboratory for Infectious Diseases, GP: general practitioner, CVZ: Care Insurance Board, NICU: neonatal intensive care unit, AH: academic hospital, MC: medical centre, GA: gestational age, GH: general hospital. The cost of preterm delivery with neonatal intensive care and high care were calculated as a weighted average of costs in a sample of 752 admissions to the NICU (26.536 euro) and high care admissions (7.248 euro). Likewise, the source of costs related to delivery between 32 and 35 weeks gestation was the Maasstad Hospital, Rotterdam.

*The workload would be mainly for midwives. The Royal Dutch Organization for Midwives assured that screening would not require extra costs as it would be part of the standard price for routine antenatal care.

**The source of costs for premature delivery and neonatal admission before 32 weeks gestation were the 2011 pricing list of the ErasmusMC, Rotterdam, and Perinatal Registries Netherlands. ${ }^{11}$ 